\title{
Institutional Racism and Ethnic Inequalities: An Expanded Multilevel Framework
}

\author{
CORETTA PHILLIPS \\ Department of Social Policy, London School of Economics and Political Science, \\ London, WC2A $2 A E$ \\ email: coretta.phillips@/se.ac.uk
}

\begin{abstract}
The concept of institutional racism re-emerged in political discourse in the late $1990 \mathrm{~s}$ after a long hiatus. Despite it initially seeming pivotal to New Labour's reform of policing and the antecedent of a new race equality agenda, it has remained a contested concept that has been critiqued by multiple constituencies. This paper notes the ambiguities and contradictions of the concept and considers its validity as an explanatory concept for long-observed ethnic inequalities in educational attainment and stop and search. In so doing, it argues for its retention, but only within a multilevel framework that incorporates racialisations operating at the micro, meso and macro levels.
\end{abstract}

\section{Introduction}

More than 25 years ago, the sociologist David Mason (1982) warned that the term 'institutional racism' would forever be a political slogan lacking in analytical rigour until it could be more precisely conceptualised, theorised and subjected to empirical investigation. The concept first appeared in the radical writings of US black political activists, Stokely Carmichael and Charles V. Hamilton in Black Power (1968). Institutional racism, it was argued, was deeply embedded in established conventions in US society, which relied on anti-black attitudes of inferiority, even if individual whites did not themselves discriminate against individual blacks. An illustration used was the high infant mortality rates of black babies resulting from insufficient nutrition, inadequate housing and poor healthcare in black neighbourhoods, which effectively operated as internal colonies. For Mason, this conceptualisation failed to provide a clear theoretical basis for specifying the mechanisms through which institutional rather than individual racism operated to disadvantage certain groups over others. Mason (1982: 44) called instead for the theoretical tools to explain 'the interplay of social structures and human action, material conditions and ideas' which could then be subjected to empirical evaluation (see also Miles, 1989; Ginsburg, 1988).

Although institutional racism was rejected as a reason for the fractured police-minority ethnic relations in Scarman's (1981) Report into the Brixton 
Disorders, by the end of the 1990 s the term had re-emerged, becoming part of mainstream political discourse when it was used to brand the Metropolitan Police Service for its failed investigation into Stephen Lawrence's racist murder (Macpherson, 1999). It provided a spur to a major reform of policing and race equality measures, although its validity was contested by sections of the rightwing press and Civitas (see for example Dennis et al., 2000), and was vehemently rejected by front-line police officers who interpreted it as meaning that individual racism within the police service was widespread (Foster et al., 2005). Similarly, academics remained sceptical because of the Macpherson definition's conflation of individual and institutional racism (Anthias, 1999; Bourne, 2001; Miles and Brown, 2003; Solomos, 1999). For Wight (2003), for example, it failed to differentiate between institutional racism as outcome and cause, recognising the agential overt and unwitting practices of individuals but not the interacting causal structural conditions (see also Bourne, 2001; Lea, 2000; Bridges, 2000).

The first part of this paper argues that, despite these conceptual ambiguities, institutional racism can be retained to assist our understanding of persistent ethnic inequalities in key areas of social policy. However, institutional racism needs to be situated within a conceptual framework which acknowledges the role of racialisation at the micro, meso and macro levels, and cannot serve as the sole explanation for the ethnically disparate welfare outcomes that have long been observed. In the second section of the paper, this multilevel framework (which includes institutional racialisation) is applied to explain ethnic ${ }^{1}$ inequalities in education (attainment) and policing (stop-and-search practices). The paper concludes with a brief discussion of the possible intervention points which may contribute to the elimination of ethnic inequalities at the micro, meso and macro levels.

Rattansi (2005) has advocated using the concept of racialisation ${ }^{2}$ and institutional racialisation instead of racism. There are both conceptual and political advantages to adopting this conceptualisation. Analytically, according to Rattansi, racialisation provides a multi-layered and multi-dimensional frame. It can encapsulate statements which explicitly denigrate or assume the inferiority of racialised groups as well as the more implicit common sense understandings which exist within institutions. Its dynamic, as opposed to static nature, allows the intersections of race with class, gender, sexuality and nation to be incorporated into any empirical investigation, as the following example (Rattansi, 2005: 290) makes clear:

Judgements about the suitability of families wanting housing or waiting to be rehoused contain elements of norms that are classed, raced, and gendered. 'Gatekeepers', white or non-white are usually middle class and deploy criteria of acceptability such as cleanliness, style of décor, behaviour of children, size of family, the deportment of the mother, which can work against white working class, black, and Asian families. 
In this regard, it accommodates intersectional understandings which recognise the significance of seeing individuals as multiply positioned, with each identity (race/ethnicity, gender or class) irreducible to a discrete category or experience. These multiple axes of differentiation and interacting levels of disadvantage and discrimination produce complex social relations (Crenshaw, 1993; Brah and Phoenix, 2009). Analytically, such an approach can also better appreciate internal differentiation which avoids essentialising experience and recognises its historically and spatially contingent nature.

Perhaps, most importantly, politically, institutional racialisation could neatly avoid the perceived binary essence of racism and its deeply polarising effect. Policy officials and lay audiences alike may be more accepting of an explanation of ethnic inequalities in welfare outcomes that is less closely associated with intentionality and motivation, and less blaming, as Foster et al.'s (2005) study of defensive police attitudes suggested.

What follows is a reframing which accommodates the need to account for individuals' roles in implementing regulations, procedures and policies which produce unequal outcomes for particular racial and ethnic groups. It employs a multilevel framework which considers the complex configurations of identities, discrimination and outcomes at three discrete but intersecting and overlapping levels: micro, meso and macro. ${ }^{3}$ Existing conceptualisations of institutional racialisation would place it at the meso level, with microlevel racialisation constituted by individual-level practices and interactions. Macro-level racialisation takes into account structural forces beyond individual practices and institutional processes. Such an account recognises, nonetheless, that institutional processes are developed, formulated and implemented by individuals constrained or enabled by structural factors (see also Cole, 2004; Giddens, 1984). Thus, racialisation and inequalities are produced and reproduced at each of these levels in interaction.

The objective of a multilevel approach is to more clearly specify the mechanisms and interacting processes through which ethnic inequalities are reproduced and sustained in a cumulative fashion. In so doing, our conceptual and theoretical understanding of racialisation is enhanced, thus making a contribution to a discipline which has not centrally located race, ethnicity and racism in its theoretical field (F. Williams, 1989). It also seeks to counter the confusion engendered by the elision of individual and institutional forms of racialisation contained in the Macpherson Report (1999), and enunciate the points at which intervention is required at the level of policy and service provision.

\section{Racialisation at the micro, meso and macro levels Micro level}

It would be a nonsense to argue that individual prejudice and racialised discrimination are not still a part of the postcolonial condition. Even 
commentators such as Gilroy (2005: 438), who see multicultural conviviality as a defining feature of urban Britain, accept the continued presence of racism in Britain. Micro social theories which consider interpretative meaning in the social interactions of everyday life can illuminate micro-level racialisation. Faceto-face encounters and recognising the agential element of individual action has traditionally been considered within an interactionist framework, with phenomenological approaches attending to subjective views of reality, rather than objective factors (Roberts, 2006). As Lal (1995) has observed, processual understandings of race and ethnicity emphasise their historical and spatial context, and look to how culture is communicated between members through socialisation and interactive experience. Such ideas permeated the work of the Chicago School of Sociology's work on immigrants' and Southern blacks' adjustment to city life, which also examined the social distance and spatial distribution of ethnic groups (Park, 1967).

Social psychological research into prejudice and racism has pointed towards the significance of the social and cultural normative climate in which dominant ingroups (the white majority) express prejudiced attitudes, which in turn contribute to a positive self-identity (Terry et al., 2001). Studies of racist violence indicate that individual perpetrators operate within families and communities that implicitly endorse racialised prejudice and ethnic hatred (see, for example, Sibbitt, 1997). Undoubtedly, some individuals working within welfare settings will have been exposed to, and have internalised views consistent with, what has been referred to as the 'new racism', where egalitarian ideals can co-exist with an anti-Black affect that causes anxiety, distrust, fear and hostility (Augoustinos and Reynolds, 2001). Such approaches also recognise the inherent ambivalence of prejudice where individuals may hold both positive and negative attitudes towards minority ethnic groups, which may explain the complex nature of the link between racist attitudes and discriminatory behaviour (Terry et al., 2001; Pettigrew and Meertens, 1995).

Micro-level racialisation, then, is inextricably framed by the influence of familial socialisation and shared cultural values which are manifest in individuals positioned within various ethnic, classed and gendered groups. These are themselves shifting rather than static, shaping and shaped by interactions with other identity groups, and influenced significantly by local environmental conditions.

\section{Meso level}

Building on this further, the meso-analytical level is particularly concerned with situating and contextualising factors which are temporally and spatially specific. In this middle-range of theorising, the following can be considered, although this is by no means an exhaustive list: (i) socio-economic disadvantage; (ii) neighbourhood composition and effects; (iii) political, media and popular 
discourses; (iv) political incorporation and empowerment; and (v) institutional processes and practices.

A focus on socio-economic disadvantage and class has always been central to social policy's epicentre of work examining poverty, inequality and redistribution. Social policy analysts have also considered neighbourhood-level processes and the specific composition of communities, acknowledging the area-based experience of social, economic and political inequality (see for example Lupton, 2003a). The Chicago School of Sociology's more qualitative influence in analysing the dynamics of community interaction, social order and institutional arrangements, often at the neighbourhood level, also operates in this range of theorising. Political engagement has similarly been understood as a key dimension whose absence has been defined as a marker of social exclusion in a democratic society (Burchardt et al., 2002).

Political, media and popular discourses addressing race/ethnicity, inequality and racism often contribute to 'commonsense' understandings of social life, which inform processes of micro-level racialisation. Migrationary flows into both urban and rural areas, for example, have been accompanied by sentiments carefully concealed in ministers' speeches, political statements and policy documents which underline racial Otherness and project multiple negative traits on to unwelcome migrants and asylum-seekers who are viewed as welfare-dependent opportunists, rather than as potential economically profitable contributors (Schuster and Solomos, 2004). Such discourses combine with the politics of resentment (Ware, 2008) centred on the perceived unequal distribution of resources to favour minority ethnic groups and more recently concerns about Islamic terrorism. Psycho-social understandings recognise the affective and emotional component of racism, which is represented as threat, pollution and contamination by racial Others who are blamed for structural changes relating to deindustrialisation, economic inequality, housing shortage, immigration and fractured communities (Hoggett, 1992). Together such views build on anxieties about both the cultural cohesion of the nation and the believed compromises required by multiculturalism (McGhee, 2005).

Finally, institutional racialisation recognises cumulative disadvantage experienced across interrelated welfare experiences (housing, education, employment and so on), produced through institutions' routine operations, regardless of the intentionality of individual actors (J. Williams, 1985).

\section{Macro level}

Structural determinants of material conditions provide the frame through which institutional processes and practices at the meso level are enacted. Globalising forces, which have produced fundamental changes in the mode of economic production, transnational politics and the unequal distribution of resources, structure social relations in Britain as elsewhere. Major demographic 
changes wrought by migration flows within and between North and South states have resulted in diverse social groups seeking welfare services.

The nature of welfare more broadly, and housing, education and employment specifically, have also been transformed in the post-industrialised late modern world. Deindustrialisation, technological change, casualisation and part-time working, educational credentialism, marketisation, increased owneroccupation, the residualisation of social housing, the rise of the consumer/client, and entrenched inequalities of wealth, income and power have all influenced the context in which social welfare is provided and services are delivered. Added to this, the neo-liberal stamp of decentralised governance and public managerialism have dramatically altered the way in which public sector organisations are managed, which is then translated in front-line operational practices.

Goldberg's (2001) insights on the formation of the modern racial state are also valuable for our interpretive understanding at the macro level. Through its apparatuses, modern states, it is argued, shaped articulations of race and racist exclusion, through definition, regulation, management, economic controls and the mediation of social relations. Ethnic monitoring, the surveillance and criminalisation of racially identified populations, their limited access to economic resources and the extent to which such groups interacted, all served the modern racial state. Imbibed within political and popular culture, such expressions of race (typically hierarchical) are deeply rooted in Enlightenment thinking (Eze, 1997), and are acted upon, albeit reflexively, within institutions.

\section{Ethnic inequalities in education and stop and search ${ }^{4}$ practices in England: analysing the contemporary picture}

In order to move the discussion beyond abstraction, what follows is a speculative exploration of how racialisation operating interactively at the micro, meso and macro levels might assist our understanding of ethnic inequalities. I shall discuss two illustrative examples drawn from the English context: educational attainment at the end of compulsory education and police use of stop and search.

Table 1 shows the levels of attainment for different ethnic groups by gender in 2008. Children of Chinese, Indian and Mixed White and Asian origin perform at the highest levels with the most five $\mathrm{A}^{*}-\mathrm{C}$ passes at GCSE level. In contrast, children of Irish Traveller and Gypsy/Roma heritage have very low levels of attainment, and those of Black Caribbean, Mixed White and Black Caribbean and Other Black origins also have fewer gaining the standard measure. The table also reveals the out-performance of boys by girls in all ethnic groups.

The explanatory frameworks proposed to explicate these differential outcomes have included variants of socio-economic/class disadvantage and teacher/school racism, which can be placed within the micro-meso-macro framework. Before doing this, it is necessary to consider David Gillborn's thesis 
TABLE 1. Percentage of pupils achieving $5+A^{*}-\mathrm{C}$ GCSE passes in England (2008)

\begin{tabular}{lccc}
\hline & Girls & Boys & Total \\
\hline White & 69 & 60 & 64 \\
White British & 69 & 60 & 65 \\
Irish & 74 & 64 & 70 \\
Traveller of Irish Heritage & 20 & 16 & 18 \\
Gypsy/Roma & 20 & 13 & 16 \\
Other White & 66 & 58 & 62 \\
Asian & 73 & 63 & 68 \\
Indian & 83 & 75 & 79 \\
Pakistani & 65 & 54 & 59 \\
Bangladeshi & 69 & 57 & 63 \\
Other Asian & 73 & 62 & 67 \\
Black & 65 & 52 & 59 \\
Caribbean & 62 & 49 & 55 \\
African & 68 & 55 & 62 \\
Other Black & 64 & 51 & 58 \\
Mixed & 68 & 59 & 64 \\
White and Black Caribbean & 61 & 51 & 56 \\
White and Black African & 68 & 61 & 64 \\
White and Asian & 76 & 69 & 73 \\
Other Mixed & 72 & 62 & 67 \\
Chinese & 88 & 81 & 85 \\
Other & 66 & 56 & 61 \\
\hline
\end{tabular}

Note: Percentages have been rounded.

Source: DCSF (2009).

(2008), which posits a central role for institutional racism in explaining minority ethnic underachievement.

\section{David Gillborn's (2008) coincidence or conspiracy?}

Utilising the tenets of Critical Race Theory and Roithmayr's (2003) concept of 'locked-in inequality', Gillborn (2008) argues that the achievement gap is a permanent feature of the English education system. Historical discrimination against minority ethnic groups has been institutionalised so that even when contemporary barriers to equality are removed, persistent inequality remains.

Gillborn's attention is specifically focused on educational practices, such as setting, coaching and examination tiering, which it is argued cumulatively disadvantage black pupils. Allocated to lower sets in maths, black pupils are then more likely to be entered into the Foundation tier for maths and English compared with their white counterparts. This amounts to a crucial lowering of academic possibilities, as pupils cannot be awarded higher grades which facilitate access to higher education and professional careers. This led Gillborn (2008: 97) to forcefully argue that ' $\mathrm{i}$ ]t is difficult to think of a clearer example of institutional 
racism than a test, disproportionately taken by Black students, in which the highest possible grade is commonly judged to be a "failure".

Valuably, Gillborn (2008) also draws our attention to the way in which previous 'knowledge' about educational attainment in pre-school children, which showed black pupils to be performing well (using baseline assessments), has been 'rewritten'. Instead, using the Foundation Stage Profile, which is based on teacher judgements, lower levels of early achievement among black pupils have been recorded. The enormity of this is self-evident: policy discourse now assumes a static level of black underachievement all through the education system, which deflects attention away from the role of the school in contributing to ethnic inequalities in education.

Gillborn's (2008) powerful insight into contemporary processes of schooling that reproduce and sustain inequality can be complemented by teasing out practices which additionally contribute to unequal outcomes, but which can be more precisely conceptualised as occurring at the micro meso and macro levels. It can accommodate the idea of multiple racialisations, something which Critical Race Theory, used by Gillborn, has been critiqued for not doing sufficiently, as well as incorporating intersectional explanations (Rizvi, 2009). The application of the multilevel framework is presented below as an attempt to make explicit the cumulative layering of racialised disadvantage, whilst also avoiding the conflation of individual-level and institutionalised racialisation. In so doing, it specifies exactly how individual actions are framed by structural and material conditions, which are themselves built upon complex and shifting ideas about human groupings that are rooted in assumptions about racial hierarchies.

\section{Applying the multilevel framework: educational attainment}

At the level of the individual teacher (micro), racialised interactions that rely on essentialist notions of race, ethnicity and culture may taint the educational experience of some pupils who are discriminated against. In this account, the 'unwitting prejudice, ignorance, thoughtlessness and racial stereotyping' described in the Macpherson (1999: 6.34) element of institutional racism is redefined as micro-level racialisation, which can take account of multiple subject positions, including gender, class and religion.

Favourable ${ }^{5}$ racialised stereotyping in the case of Chinese pupils and more negative racialisation where black Caribbean, black African and certain South Asian origin pupils are concerned have been documented in research studies. Such representations draw loosely on behavioural attributes, which appeared in Enlightenment classificatory systems that erroneously saw human phenotypical groupings scientifically categorised in an hierarchical Great Chain of Being to God. De Gobineau's (1853) classification, to name one example, referred to the Yellow race as tending towards apathy, lacking physical strength, having an obstinate will, but being theoretical and respecting the law. The black race, at 
the lowest end of the hierarchy was marked by animalism, limited intellect, great energy, wild desire and will, unable to distinguish between right and wrong. For de Gobineau, the White race had energetic and superior intelligence, perseverance, great physical power and an instinct for order. These bear a striking resemblance to contemporary racialised stereotypes, although at times these have been positively recast, as in the case of popular and commodified street culture associated with an essential blackness (Hill Collins, 2006).

According to Archer and Francis (2005a), representations of Chinese pupils' academic abilities derive from teachers' understandings of 'Chinese culture', which assumes high parental expectations, the valuing of education and stable family structures. These are seen as promoting obedience, respect and competition, as well as an appetite for educational success, which is supported through high teacher expectations, which have been linked to educational attainment (Mortimore et al., 1988; OFSTED, 1999). Stereotypes of Chinese girls may include more negative elements, assuming passivity and patriarchal dominance.

In contrast, Youdell's (2003) work reveals an inversion of the 'coolness' of black male identities within youth subcultures by some teachers who reproduce black boys as challenges to authority (see also Frosh et al., 2002). Bodily and linguistic practices are often negatively interpreted as culturally deficient and then constituted by the school's organisational discourse as anti-school and incompatible with active learning, and this can extend to black girls too. Thus, micro-level actions are constituted by, and reinscribe, meso-level racialisation rooted in political and popular discourses, which typify young black men as hyper-sexual, aggressive and criminally violent (Alexander, 1996; Murji, 1999). It is also perhaps in this context that black anti-school masculinities are manifested, as any resistance to these micro-racialising practices by black pupils further entrenches negative labelling in a teleological manner (see Sewell, 1997, 2000; Howarth, 2004).

Howarth (2004) too describes micro-teaching practices and behaviour management, which implicitly inscribe white British cultural dominance in dismissing the significance of Somali cultural practices, such as looking down when spoken to by adults as a sign of respect and deference - without meaningful cultural understanding, this is interpreted by British teachers as defiant and disrespectful.

For South Asian Muslim boys, teacher perceptions appear to be overly concerned with their presumed fundamentalist beliefs, patriarchal orientation, perceived self-segregation and violence (Archer, 2003; Crozier and Davies, 2008). Constructions of the identities of South Asian girls position them as passive and oppressed in their home lives, despite more agential understandings of the various coping strategies which may be employed to overcome experiences of schooling which are shaped by racism in school and wider society (Shain, 200o). 
According to Reay (2009), white working-class children have historically been depicted as culturally inferior and requiring control and surveillance in the state education system. Such ideas permeate educational practices in the contemporary period, contributing to a pathologisation of white and minority ethnic workingclass children as unmotivated, unambitious and educational 'losers' set against middle-class 'winners' (see also Lupton, 2003b).

Decision-making by teachers - for example, choosing not to fully support and educationally challenge an individual pupil - may be influenced by these generalised and imprecise representations. This also undoubtedly contributes to the disproportionately high exclusion rates among black pupils (DCSF, 2007), which has a deleterious effect on pupils' school careers and later employment opportunities, even though evidence suggests black excluded pupils are of aboveaverage academic ability (OFSTED, 1999). Further empirical work exploring the subjective interpretations of teachers in these micro-interactions could valuably provide an insight into intervention possibilities.

At the meso level, class and socio-economic disadvantage have also been at the heart of sociological explanations of educational underachievement. Strand's (2008) analysis using the Longitudinal Study of Young People in England showed that low socio-economic status contributed most to White British lower levels of attainment for boys and girls, but was also an issue for black boys. Additionally, black pupils from middle and high socio-economic status homes underachieved in relation to White British pupils, despite high levels of commitment to education.

For white pupils from lower socio-economic status families, Strand (2008) found that low educational attainment was mediated through lower parental and pupil aspirations for educational success and a low academic self-concept (see also Lupton, 2003b). This is consistent with Reay's (2009) observation that many white working-class children have been made to feel educationally worthless. Evans' (2007) bio-ethnography on an inner London housing estate has also suggested that white working-class educational underachievement can be partly attributed to formal learning rarely being practised in the home even though education is highly valued. As Reay has noted, working-class children are less likely to have access to private tuition and the culturally enriching activities that can be provided by middle-class parents. Additionally, for boys, according to Evans, masculine identification was associated with fighting and toughness rather than educational success, while Frosh et al.'s. (2002) earlier work indicates a clear polarisation between popularity and schoolwork. For Reay (2009: 27), working-class pupils, '[ $\mathrm{f}$ ] acing an educational competition they cannot win [they] construct peer group macho and physically aggressive competitions where some of them can and do win'. Theorised by Garner (2007) as contingent hierarchies, white working-class identities have been pathologised in specific historical and spatial contexts, with labels from academia ('underclass') and popular 
consciousness ('chav') invested with the same lesser and blameworthy status (Haylett, 2001).

Relatedly, parental disengagement with schools, also seen to influence educational outcomes, can be related to socio-economic and class disadvantage, given the middle-class milieu of the school and increased pressure to make parents responsible for their children's learning (Ball, 2003). This falls within the category of political incorporation and empowerment, which is itself subject to stratifying processes. The demands of contemporary employment for men and women may militate against active engagement by parents, which will impact most on minority ethnic and migrant groups because of their racialised disadvantage in the employment field (Heath and Cheung, 2006). Language and cultural barriers, particularly in multi-ethnic and multi-faith urban schools, may also inhibit active parent-school links (Lupton, 2003b). The latter two possibilities are structured by macro-level features of contemporary British society which lie beyond the institution. Finally, the legacy of more blatant forms of racism, experienced by today's parents (as children), as well as fears about the effects of negative stereotyping on their children may also be a contributory factor in poor home-school interactions involving black parents (Crozier, 2005).

For a whole variety of reasons - including economic constraints, access to housing, racist violence and racialised clustering choices - Britain's neighbourhoods have ethnically concentrated populations, particularly for South Asian communities (Lupton and Power, 2004). Johnston et al. (2004) have found that pupils of Indian, Pakistani, Bangladeshi and to a lesser extent black origin attend more ethnically segregated schools than would be expected by their representation in local neighbourhoods. Thus, concentrations of pupils whose attainment levels are average or below average are educated in schools where they form a significant proportion of pupils. Facilitated by school choice policies, this is indicative of ethnically informed choosing and class bias by parents (Tomlinson, 1998). Such practices defy a dichotomous analysis of racism per se, but correspond with a heavily racialised process that occurs at the interaction of class and state educational policies.

Similarly located at the meso level are the cultural practices of minority ethnic groups, which may militate against educational success. Abbas' (2002) examination of South Asian engagement with education suggested the greater time commitment required for Muslim religious observance compared with Hindu or Sikh religious observance might contribute to poorer educational outcomes (see also Lupton, 2003b, cf. Crozier and Davies, 2008).

The situational context of the school has also been shown to impact teaching quality, and such contextual effects are classed and racialised. Lupton's (2003b) examination of four secondary schools in very deprived areas revealed numerous obstacles and disruptions to teachers' academic activities. Specialised teaching materials for lower ability children often had to be constructed, vulnerable 
children required emotional support, and basic learning and extra-curricular activities were constrained by the material poverty of parents.

A more precise analysis of the role of institutional racialisation is proposed that seeks to avoid the conflation of previous definitions, instead analysing the routine bureaucratic processes and institutional practices that reinforce inequalities structured through ethnicity. It is here that Macpherson's (1999) notion of the 'collective failure of an organisation to provide an appropriate and professional service to people because of their colour, culture or ethnic origin' can be utilised.

An ethnocentric curriculum or extra-curricular activities which do not take at face value the government's assertion that 'Britishness encompasses the collective contribution diverse communities make to the country' (Home Office, 2005) is an example of institutionalised discrimination (Searle, 2001). Failure to provide positive and meaningful representations of members of the white working-class in schooling (Reay, 2009) can be similarly defined. For Warren (2007), such practices rest on a culturalist logic which privileges certain kinds of white hegemonic knowledge based on racial, classed and gendered differentiation. School dress regulations, which prohibit certain kinds of cultural hairstyles or religious symbols favoured by particular ethnic groups, are another example of institutional racialisation and discrimination (see Sewell, 1997). The incompatibility of performance and attendance targets with an inclusive delivery of the curriculum to nomadic Gypsy/Traveller children is a further illustration (Cudworth, 2008; cf. Jordan, 2001). Denying the racist motivation or failing to respond to the racist victimisation of pupils or staff represent an additional example of institutional racialisation (Crozier and Davies, 2008). All such practices encapsulate the key elements of Carmichael and Hamilton's (1968) definition which sees racial inequalities being produced through routine institutional practices, regardless of intentionality, rooted in the historical process of racialised (and classed) exclusion.

At the macro level, the neo-liberal orientation towards promoting choice for, and accountability towards, parents, established under the Conservative administration, has been further enshrined in New Labour's education policy. The language of marketisation, competition and choice is accompanied by the managerialist logic of testing and targets to raise educational standards. The corrupting effects of these policies are numerous and they stand oxymoronically alongside government discourse promoting community cohesion and social inclusion. Combined, these strands have produced corrosive effects which have entrenched racialised and classed inequalities and maintained a hegemonic position that favours the white middle class (Reay, 2008), which could be seen largely as an unintended consequence or what Parsons (2009) terms 'passive racism'. Deindustrialisation and the increased importance of educational credentials have made such processes crucial in determining 
life chances and future opportunities in employment, housing, health and leisure.

Acknowledging the interaction of micro-, meso- and macro-level racialisation enables a clearer picture of their compounding effects. Micro-level actions by teachers in the routine nature of their work are framed by state policies in education, which have privileged a neo-liberalist standards agenda in which schools are pitted against each other to secure a dominant place in local education markets. Pressure from national government, local education authorities and headteachers is likely to impel teachers to direct their efforts to the goal of improving attainment overall. As funding is dependent on enrolments, which are dependent on parental popularity, there is mutual reinforcement of a strategy in which selective targeting of some pupils over others is a 'rational' response by teachers.

Implicitly, this promotes a targeting of teacher resources at pupils not deemed undesirable or problematic learners. However, this category may not be solely objectively determined, but instead be influenced by dominant discourses that attach inferior or superior behavioural attributes to certain ethnic and class groups. A Pakistani pupil who is automatically stereotyped as an undesirable learner and allocated by a teacher to a lower academic stream is disadvantaged by micro-level racialisation. When the pupil is not entered for a higher-tier GCSE examination or coached by their school to perform at the highest level, as Gillborn and Youdell's (2000) research on rationing has indicated, it is the meso-level routine organisational practice of the school that further entrenches the disadvantage of the pupil. Further compounded by institutional racialisation, cultural practices and structural constraints, which affect school composition and parental engagement, ethnic and class-based inequalities persist in educational attainment.

\section{Stop and search}

The multilevel model can also be applied to understand ethnic disproportionality in the police use of stop-and-search powers in England and Wales. Figures for 2007/8 show that the rate of stop and search using powers under Section 1 Police and Criminal Evidence Act $1984^{6}$ was 7.6 (black) and 2.3 (Asian) times higher than for white people (Riley et al., 2009). This long-observed ethnic disproportionality can be partially attributed to micro-level racialisation and discrimination by individual police officers on the street. Stereotypes posit black people as criminally disposed, drug-abusing and violent, which can be traced back to the classificatory systems of Enlightenment thinkers (de Gobineau, 1853). Asian men have increasingly come to be perceived as disorderly, militant, culturally separatist and inclined towards Islamic terrorism (Phillips and Bowling, 2007). Even the Macpherson Report (1999: para. 45.10) acknowledged that 'the majority of police officers who testified before us accepted that an element of the disparity 
was the result of discrimination'. This is not, of course, to deny that black people's elevated rates of offending in relation to 'street crime' is a contributory factor (Phillips and Bowling, 2007).

At the meso level, racialisation structured through socio-economic disadvantage and social class comes into play. Black people's greater 'availability' on the streets - because of higher levels of school exclusions and unemployment combined with their residential concentration in higher crime areas - contributes to disproportionality in stop and search (Waddington et al., 2004). Political and media discourses on urban crime problems have cemented in the public mind a link between violence, gangs and minority ethnic, particularly black, individuals and communities (Sveinsson, 2008).

The study of police organisational cultures has also consistently shown racial prejudice as a defining and taken-for-granted feature of 'cop culture' (Reiner, 1992). Loftus' (2008) recent research indicates that the white, male, heterosexual interior culture of the police is resisting the new diversity and equalities policing agenda post-Macpherson. Interacting at the micro-meso levels, translated into operational practice, police officers may rely on unquestioned racialised stereotyping as they confront the 'mean streets' and battle crime, particularly where they perceive challenges to their authority and status (Foster, 2003; cf. Smith and Gray, 1983). For Jefferson (1993), age, sex, class, situation, demeanour and attitude determine who the police define as a trouble-making 'toe-rag', arguing this is a generic rather than racialised category. Such a reductionist explanation does, however, negate the relative autonomy of racism from economic and political relations (CCCS, 1982).

In relation to institutional practices, there is some evidence that stopand-search rates are higher in certain residential areas where there is not the concomitant crime levels (MVA and Miller, 2000). Moreover, whilst 'racial profiling' is not officially sanctioned, it appears to be unofficially practised as stop and search is a perceived indicator of performance by police officers. Minority ethnic police officers have reported advisory comments by colleagues, such as 'if you see four black youths in a car, it's worth giving them a pull, as at least one of them is going to be guilty of something or other' (Cashmore, 2001: 652). Police legitimacy in minority ethnic communities is seemingly sacrificed even though stop and search has an extremely limited impact on crime disruption and detection (Miller et al., 200o), despite this being the official justification for its continuance.

Such practices coalesce with the dominant currents of macro-level racialisation in crime control which sees the increasing intolerance towards, othering and criminalisation of, socially, economically and politically marginalised groups. In a climate of material and ontological insecurity, resulting from a pluralism of values and identities, where informal social control has fractured, and populist punitiveness is buoyed by an insatiable media and politic, 
resentment is rife and the deviance of the relatively deprived is harshly punished by the criminal justice system (Young, 2007). This can be seen in the massive overrepresentation of minority ethnic people in prison. Periodic moral panics about black street crime and violence echo the long-heard claims of an essentialist 'black criminality' (Gilroy, 1982). Similarly constructed are the political concerns over the criminality or extremism of immigrants. These features sustain institutional practices, propelled by a managerialist preoccupation with policing performance indicators and targets, framing micro-level racialisation by individual police officers encountering minority ethnic citizens on the street.

\section{Concluding comments}

In recognising the conceptual and practical limitations of institutional racism, this paper has proposed an alternative multilevel framework to explain ethnic inequalities in welfare outcomes. Recognising intersecting cultural, material, ideological, institutional and structural elements of racialisation can enhance our conceptual and theoretical understanding. It takes us beyond an approach which privileges institutional factors and instead recognises the significance of micro-racialisation expressed at the individual level and the macro-racialising tendencies of late modernity. This framework can accommodate changes in factors at each level, but it does implicitly assume multicausal explanations for inequalities in outcomes.

Additionally, this approach provides potential intervention points for policy makers and service providers working towards eliminating inequality. Directly tackling everyday micro-level racialisation by service providers (teachers, police officers, housing officers and so on) is a crucial first step, recognising conscious or unconscious processes of hierarchicalisation that individuals utilise. At the micromeso interaction, management oversight of allocation to tiers or streams, and the use of stop-and-search powers by individual officers could reduce the cumulative effects of racialised stereotyping. At the meso level, critically scrutinising routine practices of institutional racialisation should form part of the 'racial-proofing' of policies under the Race Relations Amendment Act 200o. In education, this could relate to the curriculum, behaviour management, uniform, delivery of education, and so on, whilst in policing this could mean decoupling performance indicators from practices which have targeted racialised groups. At the meso-macro level, limiting parental choice policies to produce a more even spread in pupil intakes (in terms of ability and advantage/disadvantage) could counter some of the harmful effects of neo-liberalist education policies (Education Research Group, 2009), which stand in contradistinction to the inclusion, equality and community cohesion agendas. Similarly, increasing police legitimacy in minority ethnic communities should be regarded as inextricably linked to controlling crime, thus requiring a less alienating and criminalising approach to policing Britain's 
multicultural society. Both necessitate a political discourse that does not sacrifice equality and social cohesion to the more dominant and punitive trends in both education and criminal justice.

\section{Acknowledgements}

I am grateful to the Journal of Social Policy reviewers. Their comments on an earlier version of this paper have improved it significantly.

\section{Notes}

1 For consistency purposes, 'ethnic' is used here because the main statistical sources of evidence on unequal welfare outcomes draw on official categories that make reference to ethnic origins, groups or appearance. That said, these categories do largely rely on phenotypical markers usually denoting biological racial origins. Elsewhere, the paper refers to 'racial' inequality because that has been the term typically used by proponents of the institutional racism thesis (e.g. Carmichael and Hamilton, 1968).

2 This is different from Miles' (1989) Marxist conceptualisation (see also Cole, 2004).

3 This approach is similar to Ginsburg's (1988) attempt to categorise racism at the subjective, institutional, and structural levels in examining council housing, and Wight's (2003) conceptual agent-structure Bourdieuian analysis. It extends these by differentiating institutional racialisation from that occurring at the micro and macro levels, and goes on to consider two social policy arenas, as well as providing a suggested path to rigorous empirical work.

4 Data on stop and search practices is for England and Wales.

5 Even externally favourable stereotyping can negatively homogenise individuals and mask internal variation and inequalities (see Archer and Francis' 2005b).

6 These are among the most frequently used stop and search powers. The power assists police officers to allay or confirm suspicions about individuals without using their arrest powers.

\section{References}

Abbas, T. (2002), 'The home and the school in the educational achievements of South Asians', Race Ethnicity and Education, 5: 3, 291-316.

Alexander, C. (1996), The Art of Being Black, Oxford: Oxford University Press.

Anthias, F. (1999), 'Institutional racism, power and accountability', Sociological Research Online, 4: 1.

Archer, L. (2003), Race, Masculinity and Schooling, Maidenhead: Open University Press.

Archer, L. and Francis, B. (2005a), "They never go off the rails like other ethnic groups': teachers' constructions of British Chinese pupils' gender identities and approaches to learning', British Journal of Sociology of Education, 26: 2, 165-82.

Archer, L. and Francis, B. (2005b), 'Challenging classes? Exploring the role of social class within the identities and achievement of British Chinese pupils', Sociology, 40: 1, 29-49.

Augoustinos, M. and Reynolds, K. J. (2001), 'Prejudice, racism and social psychology', in M. Augoustinos and K. J. Reynolds (eds.), Understanding Prejudice, Racism, and Social Conflict, London: Sage.

Ball, S. (2003), Class Strategies and the Educational Market: The Middle-Classes and Social Advantage, London: Routledge.

Bourne, J. (2001), 'The life and times of institutional racism', Race and Class, 43: 2, 7-22.

Brah, A. and Phoenix, A. (2009), 'Ain't I a woman? Revisiting intersectionality', in E. Taylor, D. Gillborn and G. Ladson-Billings (eds.), Foundations of Critical Race Theory in Education, New York, NY: Routledge. 
Bridges, L. (2000), 'The Lawrence Inquiry-incompetence, corruption and institutional racism', Journal of Law and Society, 26: 3, 289-322.

Burchardt, T., Le Grand, J. and Piachaud, D. (2002), 'Degrees of exclusion: developing a dynamic, multidimensional measure', in J. Hills, J. Le Grand and D. Piachaud (eds.), Understanding Social Exclusion, Oxford: Oxford University Press.

Carmichael, S. and Hamilton, C. (1968), Black Power: The Politics of Liberation, Harmondsworth: Penguin.

Cashmore, E. (2001), 'The experiences of ethnic minority police officers in Britain: underrecruitment and racial profiling in a performance culture', Ethnic and Racial Studies, 24: $4,642-59$.

CCCS (1982), The Empire Strikes Back: Race and Racism in 7os Britain, London: Hutchinson, in association with the Centre for Contemporary Cultural Studies.

Cole, M. (2004), "Brutal and stinking" and "difficult to handle": the historical and contemporary manifestations of racialisation, institutional racism and schooling in Britain', Race, Ethnicity and Education, 7: 1, 35-56.

Crenshaw, K. (1993), 'Mapping the margins: intersectionality, identity politics, and violence against women of color', Stanford Law Review, 43: 6, 1241-99.

Crozier, G. (2005), “'There's a war against our children': black educational underachievement revisited', British Journal of Sociology of Education, 26: 5, 585-98.

Crozier, G. and Davies, J. (2008), “"The trouble is they don't mix": self-segregation or enforced exclusion?', Race Ethnicity Education, 11: 3, 285-301.

Cudworth, D. (2008), "There is little bit more than just delivering the stuff": policy, pedagogy and the education of gypsy.traveller children', Critical Social Policy, 28: 3, 36177 .

DCSF (2007), Permanent and Fixed Period Exclusions from Schools and Exclusion Appeals in England 2005/06, Statistical First Release, London: DCSF.

DCSF (2009), Attainment by Pupil Characteristics, in England 2007/08 (National Indicator 108: Key Stage 4 Attainment for Black and Minority Ethnic Groups $-5+A^{*}-C$ GCSEs Including English and Maths), London: DCSF, www.dcsf.gov.uk/rsgateway/db/sfr/ sooo822/index.shtml.

Dennis, N., Erdos, G. and Al-Shahi, A. (2000), Racist Murder and Pressure Group Politics: The Macpherson Report and the Police, London: Institute for the Study of Civil Society.

Education Research Group (2009), Attainment Gaps between the Most Deprived and Advantaged Schools, London: Sutton Trust.

Evans, G. (2007), Educational Failure and Working Class White Children in Britain, Basingstoke: Palgrave Macmillan.

Eze, E. (1997), Race and the Enlightenment: A Reader, Oxford: Blackwell.

Foster, J. (2003), 'Police cultures', in T. Newburn (ed.), Handbook of Policing, Cullompton: Willan Publiishing.

Foster, J., Newburn, T. and Souhami, A. (2005), Assessing the Impact of the Stephen Lawrence Inquiry, Home Office Research Study 294, London: Home Office.

Frosh, S., Phoenix, A. and Pattman, R. (2002), Young Masculinities, Basingstoke: Palgrave.

Garner, S. (2007), Whiteness: An Introduction, London: Routledge.

Giddens, A. (1984), The Constitution of Society, Cambridge: Polity.

Gillborn, D. and Youdell, D. (2000), Rationing Education: Policy, Practice, Reform and Equity, Buckingham: Open University Press.

Gillborn, D. (2008), Racism and Education: Coincidence or Conspiracy, London: Routledge.

Gilroy, P. (1982), 'Police and thieves', in Studies, Centre for Contemporary Cultural Studies (ed.), The Empire Strikes Back; Race and Racism in 70 s Britain, London: Routledge.

Gilroy, P. (2005), 'Multiculture, double consciousness and the "War on Terror'”, Patterns of Prejudice, 39: 4, 431-43.

Ginsburg, N. (1988), 'Institutional racism and local authority housing', Critical Social Policy, 8: 24, 4-19.

de Gobineau, A. (1853), The Inequality of Human Races, New York, NY: Howard Fertig.

Goldberg, D. T. (2001), The Racial State, Oxford: Wiley-Blackwell. 
Haylett, C. (2001), 'Illegitimate subjects? Abject whites, neoliberal modernisation and middle-class multiculturalism', Environment and Planning D: Society and Space, 19: $351-70$.

Heath, A. and Cheung, S. (2006), Ethnic Penalties in the Labour Market: Employers and Discrimination, Research Report No. 341, London: Department for Work and Pensions.

Hill Collins, P. (2006), 'New commodities, new consumers: selling blackness in a global marketplace', Ethnicities, 6: 3, 297-317.

Hoggett, P. (1992), 'A place for experience: a psychoanalytic perspective on boundary, identity, and culture', Environment and Planning D: Society and Space, 10:3, 345-56.

Home Office (2005), Improving Opportunity, Strengthening Society: The Government's Strategy to Increase Race Equality and Community Cohesion, London: Home Office.

Howarth, C. (2004), 'Re-presentation and resistance in the context of school exclusion: reasons to be critical', Journal of Community and Applied Social Psychology, 14: 5, 356-77.

Jefferson, T. (1993), 'The racism of criminalization: police and the reproduction of the criminal other', in L. R. Gelsthorpe (ed.), Minority Ethnic Groups in the Criminal Justice System, Cambridge: The Institute of Criminology, Cambridge University.

Johnston, R., Wilson, D. and Burgess, S. (2004), 'School segregation in multiethnic England', Ethnicities, 4: 2, 237-65.

Jordan, E. (2001), 'Exclusion of travellers in state schools', Educational Research, 43: 2, $117-32$.

Lal, B. B. (1995), 'Symbolic interaction theories', American Behavioral Scientist, 38: 3, 42141.

Lea, J. (2000), 'The Macpherson Report and the question of institutional racism', The Howard Journal, 39: 3, 219-33.

Loftus, B. (2008), 'Dominant culture interrupted: recognition, resentment and the politics of change in an English police force', British Journal of Criminology, 48: 6, 75677.

Lupton, R. (2003a), 'Neighbourhood Effects': Can We Measure Them and Does It Matter? Case Paper 72, London: Centre for the Analysis of Social Exclusion.

Lupton, R. (2003b), Schools in Disadvantaged Areas: Recognising Context and Raising Quality, Case Paper 76, London: Centre for the Analysis of Social Exclusion.

Lupton, R. and Power, A. (2004), Minority Ethnic Groups in Britain, London: Centre for the Analysis of Social Exclusion.

Macpherson, W. (1999), The Stephen Lawrence Inquiry, Report of an Inquiry by Sir William Macpherson of Cluny, Cm 4262-1, London: Home Office.

Mason, D. (1982), 'After Scarman: a note on the concept of "institutional racism"', New Community, 10: 1, 38-45.

McGhee, D. (2005), Intolerant Britain? Hate, Citizenship and Difference, Maidenhead: Open University Press.

Miles, R. (1989), Racism, London: Routledge.

Miles, R. and Brown, M. (2003), Racism, Second Edition, London: Routledge.

Miller, J., Bland, N. and Quinton, P. (2000), The Impact of Stops and Searches on Crime and the Community, London: Home Office Policing and Reducing Crime Unit.

Mortimore, P., Sammons, P., Stoll, L., Lewis, D. and Ecob, R. (1988), School Matters: The Junior Years, London: Paul Chapman.

Murji, K. (1999), 'Wild life: representations and constructions of Yardies', in J. Ferrell and N. Websdale (eds.), Make Trouble: Cultural Representatives of Crime, Deviance and Control, New York, NY: Aldine de Gruyter.

MVA and Miller, J. (2000), Profiling Populations Available for Stops and Searches, London: Home Office Policing and Reducing Crime Unit.

OFSTED (1999), Raising the Attainment of Ethnic Minority Pupils: School and Lea Responses, London: Office for Standards in Education.

Park, R. E. (1967), On Social Control and Collective Behavior: Selected Papers, Chicago, IL: University of Chicago Press. 
Parsons, C. (2009), 'Explaining sustained inequalities in ethnic minority school exclusions in England - passive racism in a neoliberal grip', Oxford Review of Education, 35: 2, 249-65.

Pettigrew, T. F. and Meertens, R. W. (1995), 'Subtle and blatant prejudice in Western Europe', European Journal of Social Psychology, 25: 57-75.

Phillips, C. and Bowling, B. (2007), 'Ethnicities, racism, crime and criminal justice', in M. Maguire, R. Morgan and R. Reiner (eds.), The Oxford Handbook of Criminology, fourth edition, Oxford: Oxford University Press.

Rattansi, A. (2005), 'The uses of racialization: the time-spaces and subject-objects of the raced body', in K. Murji and J. Solomos (eds.), Racialization: Studies in Theory and Practice, Oxford: Oxford University Press.

Reay, D. (2008), 'Tony Blair, the promotion of the "active" educational citizen and middle-class hegemony', Oxford Review of Education, 34: 6, 639-50.

Reay, D. (2009), 'Making sense of white working class education underachievement', in K. P. Sveinsson (ed.), Who Cares About the White Working Class?, London: Runnymede Trust.

Reiner, R. (1992), The Politics of the Police, London: Harvester Wheatsheaf.

Riley, J., Cassidy, D. and Becker, J. (2009), Statistics on Race and the Criminal Justice System 2007/8, London: Ministry of Justice.

Rizvi, F. (2009), 'Review symposium - racism and education: coincidence or conspiracy?', British Journal of Sociology of Education, 30: 3, 359-71.

Roberts, B. (2006), Micro Social Theory, Basingstoke: Palgrave.

Roithmayr, D. (2003), 'Locked in inequality: the persistence of discrimination', Michigan Journal of Race and Law, 9: 1, 31-75.

Scarman, L. (1981), The Scarman Report. The Brixton Disorders, 10-12 April 1981, London: HMSO.

Schuster, L. and Solomos, J. (2004), 'Race, immigration and asylum: New Labour's agenda and its consequences', Ethnicities, 4: 2, 267-86.

Searle, C. (2001), An Exclusive Education: Race, Class and Exclusion in British Schools, London: Lawrence \& Wishart.

Sewell, T. (1997), Black Masculinities and Schooling: How Black Boys Survive Modern Schooling, London: Trentham Books.

Sewell, T. (2000), 'Beyond institutional racism: tackling the real problems of black underachievement', Multicultural Teaching, 18: 2, 27-33.

Shain, F. (2000), 'Culture, survival and resistance: theorizing young Asian women's experiences and strategies in contemporary British schooling and society', Discourse: Studies in the Cultural Politics of Education, 21: 2, 156-74.

Sibbitt, R. (1997), The Perpetrators of Racial Harassment and Racial Violence, London: Home Office.

Smith, D. J. and Gray, J. (1983), The Police in Action, London: Policy Studies Institute.

Solomos, J. (1999), 'Social research and the Stephen Lawrence Inquiry', Sociological Research Online, 4: 1.

Strand, S. (2008), Minority Ethnic Pupils in the Longitudinal Study of Young People in England: Extension Report on Performance in Public Examinations at Age 16, DCSF Rbo29, London: DCSF.

Sveinsson, K. (2008), A Tale of Two Englands: 'Race' and Violent Crime in the Media, London: The Runnymede Trust.

Terry, D. J., Hogg, M. A. and Blackwood, L. (2001), 'Prejudiced attitudes, groups norms and discriminatory behaviour', in M. Augoustinos and K. J. Reynolds (eds.), Understanding Prejudice, Racism, and Social Conflict, London: Sage.

Tomlinson, S. (1998), 'New inequalities? Educational markets and ethnic minorities [1]', Race, Ethnicity and Education, 1: 2, 207-23.

Waddington, P. A. J., Stenson, K. and Don, D. (2004), 'In proportion: race, and police stop and search', British Journal of Criminology, 44: 6, 889-914.

Ware, V. (2008), 'Towards a sociology of resentment: a debate on class and whiteness', Sociological Research Online, 13: 5, www.socresonline.org.uk/13/5/9.html. 
Warren, S. (2007), 'Migration, race and education: evidence-based policy or institutional racism?', Race Ethnicity and Education, 10: 4, 367-85.

Wight, C. (2003), 'The agent-structure problem and institutional racism', Political Studies, 51: $4,706-21$.

Williams, F. (1989), Social Policy: A Critical Introduction, Oxford: Polity Press.

Williams, J. (1985), 'Redefining institutional racism', Ethnic and Racial Studies, 8: 3, 324-48.

Youdell, D. (2003), 'Identity traps or how black students fail: the interactions between biographical, sub-cultural, and learner identities', British Journal of Sociology of Education, 24: 1, 3-20.

Young, J. (2007), The Vertigo of Late Modernity, London: Sage. 